\title{
LA TRADICIÓN LITERARIA DEL HERMAFRODITO O ANDRÓGINO
}

\author{
Kattia Chinchilla Sánchez.
}

\begin{abstract}
The following article analyses the concept of myth in literature. It specifically deals with the mythical tradition of the hermaphrodite or androgygnous in ancient and medieval times.
\end{abstract}

\section{Introducción}

No se puede abordar el estudio del mito literario si no se aborda el mito propiamente dicho. La historia de Hermafrodito y Salmacis, la significación del concepto de androginia han quedado expuestos en el artículo precedente: "La tradición mítica del Hermafrodito o andrógino en la Antigüedad y la Edad Media". Un mito literario es un mito en la literatura. Un mito, como relato y texto que es, es literatura.

Todas las religiones cuentan con mitologías y todos los pueblos con literatura (escrita u oral). En casi todos nuestros artículos hemos insistido en la necesidad de reivindicar el concepto de mito. Es difícil dar una definición que remonte la tradición negativa sobre él difundida, que satisfaga las exigencias de los eruditos y que, al mismo tiempo, sea accesible a los no especialistas.

El mito relata una historia sagrada, evidencia la sacralidad. Relata un acontecimiento acaecido en tiempos primordiales, en tiempos míticos, in illo tempore. Cuenta cómo una realidad, total o no, ha venido a la existencia. El mito es siempre un relato de creación: narra cómo algo ha sido producido y ha comenzado a ser. El mito enseña así las historias primordiales, propias del hombre de todos los tiempos: todo lo que tiene relación con su existencia en el cosmos que le concierne.

La función principal de los mitos es enunciar y fijar modelos ejemplares, tanto para los ritos como para todas las acciones humanas significativas. El andrógino, como figura mítica, es por tanto ejemplar: es un precedente para cualquier modalidad de lo real. El mito narra el origen de todos los acontecimientos primordiales, por ende, verdaderos. Como sucedieron en tiempos ancestrales y míticos, los mitos constituyen una historia sagrada, ejemplar y verdadera.

El mito relata la estructura misma de la deidad, la cual está por encima de sus atributos y reúne en sí los contrarios, es la coincidentia oppositorum, que en el hermafrodita es la fusión de lo masculino y lo femenino, los opuestos genéricos. 
Los relatos sagrados o mitos han dominado la mente del hombre de todas las épocas y han ejercido una influencia notable en las manifestaciones colectivas que llamamos cultura. Todas estas historias arcaicas, cuyo origen se pierde en la noche de los tiempos, se han proyectado en la literatura de todos los pueblos. El mundo grecolatino es el hontanar de tales relatos en Occidente. Sobra referirse aquí a la influencia casi sempiterna que esta cultura ha ejercido entre nosotros.

Para nuestro estudio tres son los relatos básicos: el Génesis, el mito platónico y la fábula de Ovidio. Los motivos colaterales a la simbología del andrógino son el huevo primordial y el concepto de cosmogonía.

En la proyección occidental del mito del andrógino son sólo algunos los textos que hemos elegido, sobre todo de la literatura francesa y varios los enfoques que analizaremos:

a. el hermafrodito como un monstruo escandaloso y libertino.

b. el andrógino como un hombre del dolor (la muerte del hermafrodita).

c. el hermafrodita como un modelo ambiguo y de plena sexualización.

d. el andrógino, una vía de perfección.

Por ejemplo, el decadentismo inglés y francés tocan el tema, pero se trata de un hermafroditismo mórbido e inclusive satánico. No se trata aquí de la plenitud debida a la fusión de los sexos, sino de una superabundancia de posibilidades eróticas. Para los escritores decadentes, el andrógino es un hermafrodita, en quien coexisten los dos sexos anatómica y fisiológicamente.

No es percibido como la aparición de un nuevo tipo de humanidad, en el cual la fusión de los sexos, habría producido una nueva conciencia, apolar, sino como una supuesta perfección sensual como resultado de la presencia activa de los dos sexos. (Eliade, 1969: 126)

\section{El monstruo escandaloso y libertino}

En el siglo XIV, El Ovidio moralizado, obra escrita en verso, brinda una traducción fiel de la Metamorfosis. Hace de Salmacis una cortesana y la presenta como responsable de la corrupción del hombre', quien se une a ella hasta formar un solo cuerpo. Vista como prostituta, ella promueve la fertilidad, por magia homeopática. Su carácter insaciable y lascivo recuerda, en algo, el poder devorador del mar y sus devaneos, el poder transformador de las aguas, representadas en Salmacis.

La idea de escándalo está relacionada con el nombre hermafrodita. Es juzgado como equívoco, herético y hasta satánico, como ya dijimos en la Introducción. Boileau, autor antibarroco, en su Sátira XII (1705), nos dice que el hermafrodito es bizarro, en su sentido francés de extravagante e impreciso (no definido):

Du langage français bizarre hermaphrodite. De quel genre te faire, équivoque maudite, ou maudit? (Boileau 1988:63). 
Aquí el autor realiza un juego de género, pues en este tiempo, esa relación era ambigua, no definida aún por la gramática francesa. Por tanto, un género indefenido es un andrógino, masculino y femenino a la vez.

En Francia, durante los siglos XVII y XVIII, se supone que el hermafrodita es homosexual, a tal grado que, en esa época, ambos sustantivos son sinónimos. Bayle señala, en su Diccionario histórico y crítico de 1697, recordando a Platón, que el nombre andrógino, en su uso corriente, era un oprobio, igual que en el texto de Platón "hermafrodita" era un insulto. Con respecto a esto, Bayle añade:

Il a raison, car outre que l'on dispute si les hermaphrodites sont des monstres, on donne ce nom aux plus infâmes débauchés. (Bayle 1988: 63).

En cuanto a su asimilación con la homosexualidad, también como oprobio, Thomas Arthus, en su panfleto L'lle Hermaphrodites (1605), utiliza el término "hermafroditas" para los "favoritos" del rey Enrique III.

Facout, en su Enciclopedia, escribe un artículo médico sobre los hermafroditos observados en su tiempo: fueron juzgados como monstruosos. Se apoya en el relato de Ovidio como etiología de este ciefecto físico.

El movimiento decadente francés se va a apoderar de esta figura andrógina, vista con su rasgo de perversidad. El hermafrodita afeminado de Albert Samain, en L'Charriot d'Or (edición póstuma de 1901), con sus espasmos lascivos y obscenos, se convierte en una especie de anticristo, que predica un placer inhumano, que captura la sensualidad y el erotismo en una criatura diabólica, de apariencia cruel y de ojos grandes y fosforescentes ${ }^{2}$.

En la novela del checoslovaco Milan Kundera, La insoportable levedad del ser, se hace referencia explícita al mito de los andróginos de Platón. Teresa, uno de los personajes, tiene un sueño: ella y su marido serían transformados en criaturas hermafroditas. Ella lava y baña a otras mujeres, en lo que sería un juego erótico común. He aquí el rasgo erótico de las aguas y sus poderes que transforman y disuelven, que bien nos recuerdan las posturas de Estrabón y Vitrubio cuando hablaban de tales prodigios en la fuente Salmacis. Este sueño erótico surrealista conjuga los fantasmas lascivos y escabrosos que buscan obtener la coincidentia oppositorum sólo por los medios de la imaginación, de lo inconsciente, sin duda colectivo y arquetípico. Alcanzar la integración absoluta (selbst) implica anular los atributos genéricos. Tal y como lo afirma Jung, el varón debe integrarse con su anima que es femenina y en la mujer, lo contrario, su animus es masculino. El hermafrodita es la materialización plástica y mítica de tal conjunción, que, en planos cotidianos, se obtiene al formar parte de la pareja heterosexual, que, con el tiempo, evidencia la transferencia de ciertos atributos que eran individuales.

\section{El hombre del dolor y la muerte del andrógino}

Cuando el hermafrodita no escandaliza, provoca piedad. Un bello poema de Tristán L'Hermite, titulado "La fortuna del Hermafrodita" (1641), adaptación personal de un epigrama del poeta neolatino Pulcio, medita sobre la tragedia del héroe. Tres oráculos proferidos por Júpiter, Venus y Mercurio lo hacen heredero no de dos sino de tres naturalezas, reactualización 
probable del mito platónico. Pero es su fin, predicho por Saturno, Marte y Diana, el que hace soñar a L'Hermite. Por su triple origen, tiene una triple muerte: las aguas de la fuente se hacen turbias: un agua negra y profunda (esto se asimila con la etapa de la nigredo, en la operación alquímica, allí justamente mueren el rey y la reina que ya se han fusionado en un ser andrógino). El hermafrodita muere, en la trampa vegetal mortífera, de carácter acuático: envenenado, colgado y ahogado. Se convierte así en un hombre de dolor.

Un ser colmado de la bisexualidad entra trágicamente en la virilidad adulta. Tal es el tema de El andrógino (1890) de Péladan. Pese al título prometedor, no es sino en las últimas páginas de la novela, en las que hallamos el basamento mítico que nos interesa. Hasta ese momento, el joven Samas no había sido más que un efebo sumido en las emociones comunes de los jóvenes de su tiempo, que vivían en una escuela de jesuitas. Por fin, cuando entra en la crisis de la pubertad, dos "gyandres" (hombres de gimnasio, es decir, de la palestra, en este caso, académica) toman, como Salmacis, la iniciativa de revelar la femineidad. Aquí es donde se anuncia, en el texto, la muerte del andrógino, título de la última parte y del último capítulo. El mito literario, a la inversa del ovidiano cuando expresa la nostalgia de la integridad, está cargado del desgarro escandaloso del adolescente que llega a ser viril:

Ils souffrent, elle de ne pas comprendre, sinon qu'elle n'est pas aimés, et lui de sentir l'androgyne mourir, de devenir l'homme horrible et sexuel. (Péladan 1988: 66).

Sodoma y Gomorra, de Giraudoux (1943), tiene por objeto manifestar la muerte del andrógino, y en consecuencia, el fín de la especie humana, la ruptura de la armonía con el cosmos, esto por cuanto, el hermafrodita no es una criatura cósmica, de hecho pertenece al período del caos, donde las formas aún estaban confusas. La creación o el cosmos implica separación de los elementos fusionados en el caos, en el estado primordial, in illud tempus, existe la confluencia de atributos, entre ellos el genérico.

Este autor, influido por el pensamiento de León Hébreu, había escrito, en obras teatrales precedentes, sobre la posibilidad de reconstruir la unidad perdida, gracias a los cinturones carnosos con que Ondina quiere atraer a su amante. A sus ojos, la perfección del andrógino primitivo está perpetuada por el amor. La caída no ha tenido lugar en el pasado, sino bajo nuestros ojos. Su concepción de la creación no está lejana a la expresada en el relato del Génesis: Dios ha creado dos cuerpos gemelos unidos por tiras de carne; luego ha cortado esos lazos para reemplazarlos por la ternura. La pareja humana, en su separación, ha traído la desarticulación del mundo animal: algunos animales seguirán al hombre, otros a la mujer. Se evidencia aquí una verdadera separación de los atributos genéricos. Según su pensar, no hay posibilidad de reconstruir lo que se ha roto, se ha perdido la unidad primigenia.

La problemática de Musil en su novela El hombre sin cualidades o El hombre sin carácter (1930-1933) es un poco la misma de Giraudoux: el sueño de la unión hombre/mujer no existe más que para encubrir la imposible unión del andrógino y el cosmos. La imagen mítica del hermafrodita era una preocupación muy antigua en Musil. En 1923, compuso un poema cuyo tema es el cambio de identidad y la fusión de Isis y Osiris. Este poema anuncia el amor fraternal de la novela en cuestión. Los encuentros del héroe con la hermana olvidada encubren el 
comienzo de una aventura que debe responder a la búsqueda central, búsqueda de una totalidad imposible de aprehender en un mundo disperso. El encuentro del hermano y de la hermana está bajo el signo del reconocimiento recíproco de la otra mitad olvidada.

Agathe proclamera que leur vocation à tous deux dans le monde est seulement d'être ensemble, inactifs et plongés dans la béatitude d'être en un deux. L'androgyne est le symbole par excellence de la totalité recherchée, la fusion des contraires. Musil ne le considère donc pas seulement comme le mythe du paradoxe sexuel mais comme celui de l'impossible résolution de toutes les contradictions.(Miguet 1988: 67)

La pasión fraternal en la obra se basa en el esquema de la unidad original y del ser gemelo: disolver el principio de separación por este amor corresponde, para los dos héroes, una protesta contra el mundo. El amor del hermano y la hermana es el signo de sus dificultades en su relación con el mundo. La imagen mítica tiene también por función fijarla, el éxtasis vivido no hace más que entrever una proximidad sin mesura, según la expresión del héroe, en la ambigüedad en un estado que ni los separa ni los reúne, es una proximidad sin síntesis.

La catastrófica muerte del andrógino en el momento de la pubertad es el tema de la obra novelesca de Dominique Fernández (Proporino o Los misterios de Nápoles, 1974). El autor se identifica con la felicidad circular de los seres primitivos platónicos. Hace responsables a las mujeres de haber privado a Adán del feliz sueño paradisíaco de la indiferenciación sexual: sin ella, los hombres tendrían los dos sexos a la vez. Se reconoce aquí el deseo por la ociosidad defendido por Salmacis: la estancia apacible e integral en el Edén es homologable a la acaecida en la laguna de Caria, con la fusión de los géneros en las personas de Salmacis y Hermafrodito.

El modelo platónico es presentado de manera inversa, la brutal escisión ordenada por Zeus tiene su equivalente en la novela: es necesario que un cirujano realice una castración preservativa, como único medio de detener la evolución hacia el sexo único.

Fernández enlaza su nostalgia por las antiguas cosmogonías del caos original cuando nos habla del huevo gigantesco, donde no hay ni tinieblas ni luminiscencias, ni húmedo ni seco, ni caliente ni frío, ni derecha ni izquierda.

\section{El hermafrodito como modelo ambiguo}

El la literatura italiana, desde Dante hasta Marino, el andrógino es un modelo ambiguo o equívoco que llega a ser la metáfora de una empresa literaria. En Dante encontramos una alusión al mito que presenta una característica muy particular: en el último círculo del Purgatorio, donde las almas de los lujuriosos cumplen su castigo, Dante se encuentra con dos tropas de penitentes, que caminan en sentido contrario. Se trata, por una parte, de los sodomitas y, por otro, de aquellos que se autodefinen así: "nuestro pecado fue ser hermafroditas" (Purgatorio, XXVI, 82). Se evidencia la oposición entre estos últimos penitentes y los sodomitas; los comentaristas suponen aquí una metáfora de la normalidad sexual desarreglada y concluyen que se les llamaba hermafroditas a los libertinos. Pero esta interpretación se topa con una incongruencia, ya que 
entre los hermafroditas se encuentra Pasífae, símbolo clásico de la bestialidad en el amor ${ }^{3}$, no se puede, según este esquema, admitir como una figura de la normalidad.

Relacionando esta metáfora de Dante con la tradición alegórica, se puede ver allí un símbolo de unión del alma y el cuerpo, o bien, concretamente, la parte divina que está en el hombre (Hermes es el dios del intelecto, pero ingenioso y un dios psicopompo ${ }^{4}$ y Pasífae es la hija del Sol). La parte divina se une a la animal (deseos e instintos). Así, el Minotauro, producto de los amores de Pasífae con un toro, se emparenta con Hermafrodito, éste ni hombre ni mujer, aquél un monstruo híbrido ni hombre ni animal. Desde esta perspectiva ambos son monstruos, pues no cumplen a cabalidad con su naturaleza.

Por otra parte, las almas hermafroditas son de los poetas, aquellos que Dante reconoce por sus maestros (los trovadores del "dolce stil nuovo"). Parecería, entonces, que el Paraíso les es negado porque los temas amorosos de su poesía intentan conciliar el amor profano y el amor sagrado que constituyen para Dios un crimen de presunción. La poesía es así definida, por la metáfora del hermafrodita, como un lazo de tensión, de dualidad, y los poetas son aquellos que creen posible la conjunción de dos fuerzas opuestas que deberían estar desunidas, aquellas de la inspiración hacia lo alto y hacia lo bajo.

En el Capítulo XXV de Orlando furioso (1532) de Ariosto, Bradamante, joven amazona, quien conduce a los caballeros, está siempre vestida de hombre, pero está enamorada de Roger. Ella tiene también un hermano gemelo que le es perfectamente idéntico y con el cual se le confunde. Este gemelo aparece en el relato más que para jugar el rol masculino, en el sentido sexual. Bradamante inspira un amor apasionado por la princesa Flordelís (Fleur d'Epine) y esta ruega al cielo convertirse en hombre. He aquí parte del sueño de Salmacis, en el relato de Ovidio. El hermano de Bradamante, enamorado de la princesa, toma la ocasión para sustituirse por su hermana y, disfrazado de mujer durante el día, desempeña, durante la noche, su papel de hombre junto con su amante que desea ser hombre. Esto nos recuerda los ritos de androginización en la Grecia antigua, en donde la mujer se pone una barba falsa para unirse con su marido y éste se viste con atuendos femeninos. También nos recuerda un relato de las Metamorfosis de Ovidio (IX), donde Ifis es cambiado a hombre el día de sus nupcias. Hay aquí también una alusión a la aventura de Tiresias, quien conoce alternativamente los placeres de los dos sexos.

Según Ariosto, esta metamorfosis ficticia está dada en el gemelo de Bradamante y su manceba, aparte de que Bradamante practica la androginización: la metamorfosis mítica llega a ser una restitución novelesca:

Le sens de la substitution est moins ici la réunification des deux parties de l'Hermaphrodite, que le dédoublement multiplié d'une unité. (Miguet 1988: 69).

En el Adonis de G.B. Marino (1623), Hermafrodito juega un papel importante, pues es Adonis mismo quien aparece como una criatura andrógina ${ }^{5}$ : es descrito según el código tradicional del madrigal, de carácter idilíco, con atributos femeninos (tez de lis y de rosa) y su belleza como la de la Aurora. Su pasividad erótica frente a la iniciativa audaz de Venus, es aquella de una virgen, o una ninfa como Salmacis. Por otra parte, en el poema, el rol de Hermes, como el de Afrodita, es de iniciador (de padre y madre espirituales). Todo el texto demuestra que los principios masculinos y femeninos no son opuestos sino que se confunden. Como para Dante, pero desde otra perspectiva, la obra de Marino se define como una tentativa de conjunción de contrarios. 


\subsection{El andrógino, un ser en plena sexualización}

Lautréamont, en los Cantos de Maldoror (1869), sostiene que Hermafrodito tiene un lazo privilegiado con la luna, como lo sostenía Platón. Su edad de adolescente y su historia pasada (los largos años de errar solitario lejos de sus padres y la estancia en la montaña) están presentes, recordándonos al héroe de Ovidio. Pero tiene una "costilla" de Salmacis: su cabellera está erotizada, como la de su compañera mítica. La naturaleza de este Hermafrodito no es asexuada, sino que posee en plenitud una sexualidad completa y única; desde su perspectiva, él no es un monstruo, pero sí lo es a los ojos de los demás:

Sans doute le personnage de Lautréamont n'a-t-il pas la disgrâce d'être asexué. Il possède en plénitude une sexualité et une affectivité d'homme et de femme: en lui se joignent "energie virile" et "grâce". Loin d'être castré, il a unee double postulation érotique; son malheur vient d'une solitude à laquelle il ne consent pas et du sentiment d'être monstrueux, non àses propes yeux, mais vis-àvis des autres. (Miguet 1988: 65)

Ante todo esto y más generoso que su modelo ovidiano, él no toma su soledad y amargura más que para sí mismo, negando toda agresividad para con sus semejantes o para con la providencia.

La heroína imaginada por Gautier en la novela que lleva su nombre, La señorita de Maupin (1835-1836), entrevé la posibilidad ideal de asumir las funciones de los dos sexos: absorberlos e irradiarlos continuamente, ser tanto la luna como el sol (lo femenino y lo masculino), ver todo el mundo y toda la creación en un solo ser:

Je suis d'un trosième sexe à part qui n'a pas encore de nom (...) j'ai le corps et l'âme d'une femme, l'esprit et la force d'un homme, et j'ai trop ou pas assez de l'un et de l'autre pour me pouvoir accoupler avec l'un eux. (Gautier, 1918: 65).

Dividida ella misma como las mitades del ser de Platón, ella no puede reencontrarse con una o con otra parte, lo que le permitiría rehacer su unidad. Sobre los compañeros viriles, entre los cuales trata de optar por su integración, afirma que ellos:

(...) sont propres à mille excepté cependant à une seule pour lauquelle ils ont été crées qui est de servir de mâle à l'animal appelé femme, avec lequel ils n’ont pas le plus léger rapport, ni physique ni moral. (Gautier, 1919: 65).

\section{El andrógino, una vía de perfección}

En la Historia cómica de los estados e Imperios del Sol (edición póstuma en 1661), Cyrano de Bergerac nos suministra una de las más eufóricas palingénesis del mito de Hermafrodito y Salmacis. Muestra dos árboles gemelos que se esfuerzan por la unidad. Estos árboles son el producto de la metamorfosis de Orestes y Pílades y sus frutos constituyen un filtro mágico con el que se unieron Tristán e Isolda. La ingesta de frutos gemelos hace renacer los compañeros 
amorosos de la epopeya; se ven multiplicar así los Aquiles y los Patroclos, los Nisos y los Euríalos, pero se ven también unas parejas incestuosas y anómalas: Cíniras y Mirra ${ }^{6}$, la joven hija y un toro, un hombre y un mármol (Pigmalión y su estatua, este relato está en las Metamorfosis de Ovidio, Libro X). Todas estas historias nos cuentan la abolición de los tabúes y el aniquilar las diferencias, que toma lugar en un contexto idílico y paradisíaco, la historia de Salmacis y Hermafrodito. Hermafrodito era un pastor que estaba ligado con una joven adolescente de la vecindad, llamada Salmacis. El primero consigue la recompensa por una carrera y la segunda un premio por su belleza: las manzanas gemelas y mágicas constituyen una recompensa.

Comparada con Eva por Cyrano de Bergerac, Salmacis está muy solícita a comer la manzana, fruta que la vuelve inmediatamente enamorada. Es preciso entonces la intervención de los padres de Hermafrodito que hallan ventajosa la unión de su hijo con la joven, que deben beber del jugo de la fruta de Orestes y Pílades.

Aquí en la imaginación del rol activo de los padres, el autor del siglo XVII se esfuerza en respetar las conveniencias de su tiempo y de hacer inocente a la ninfa, todo por dar a Salmacis, como en las tradiciones anteriores, un deseo apasionado por la fusión de los sexos. Ejemplo raro: esta fusión es presentada como igualmente feliz para el hombre y para la mujer que son a la vez unidos y fecundos, cosa que no ocurre en el relato de Ovidio:

Ce double je ne sais quoi gardait pourtant son unité: il engendrait et concevait, sans être ni homme ni femme (...) (Bergerac 1924: 71).

$\mathrm{El}$ hecho de ser gemelo es lo que hace mágicas las frutas ${ }^{7}$. El incesto no es solamente el sujeto de una historia que Cyrano asocia a la androginia, pero puede ser el corazón de la historia de Orestes y Pílades, los primos hermanos. ¿Será que los dos héroes se desean sexualmente y Electra es la intrusa, como en el cuento de Jorge Luis Borges? En todo caso, su deseo virtualmente homosexual y semi-incestuoso es aquí presentado como la fuente fecundante, aquella de Salmacis y Hermafrodito. En el mito literario que nos presenta Bergerac, la felicidad paradisíaca interviene tras la fusión de los seres.

La utopía de Gabriel de Foigny, La terre australe connue (1676), muestra una humanidad que ha subsistido en un estado primordial de androginia. Los hermafroditas de Foigny responden al modelo platónico, fundido con el relato del Génesis: tiene una superabundancia de vida y vigor. A sus ojos sus europeos monosexuales son medio-hombres. Como el Hermafrodito y la Salmacis de Cyrano, son fecundos y autogenéticos, pero a diferencia de aquéllos no conocen el deseo. Se reproducen por la vía del huevo. Entre los europeos corruptos y monosexuales y los australianos bisexuados, el autor ha imaginado un intermediario, el narrador Sadeur, que está, psíquicamente, dotado de los dos sexos, pero no posee el privilegio de una autarquía afectiva y sexual, prisionero de sus instintos, él va en marcha hacia la perfección, tiene la misión de descubrir los andróginos de Australia y de revelar su ideal de vida a sus compatriotas.

La ataraxia de los australianos es para Foigny, autor racionalista, una condición de su felicidad. La perfección de esta humanidad preservada en su integridad está destinada a mostrar que el mito de la caída no es universal. Bayle, en su Diccionario histórico y crítico, en el artículo "Sadeur", muestra que La terre australe remeda la imagen bíblica del Paraíso terrestre. Este cuento filosófico verifica que nosotros hemos ya constatado otras versiones de este mito literario: disipa la angustia que hace nacer la guerra de los sexos, el mito del hermafrodita no se limita a reducir las 
oposiciones entre el hombre y la mujer. Presenta varias diferencias. Primero, la oposición cristiana entre el alma y el cuerpo se decide en una especie de unidad de cuerpo glorioso y purificado: los australianos no comen carne, casi no producen excrementos e ignoran la menstruación. Los antagonismos que conocen nuestras sociedades, sobre todo entre el individuo y el grupo, se resuelven igualmente en las relaciones fraternales, casi gemelas.

Wilfredo, Winna y Serafita, en la obra de Balzac, intentan traducir las relaciones entre el hombre y el cosmos, así como un auténtico ensueño elemental de una abstracción. Sus tres héroes derivan de tres modos de seres que, según Platón, constituían la humanidad original. Que la acción sea en Noruega corresponde al deseo de Balzac de recrear un clima primitivo y exótico. De los seres primordiales que nos describe Platón, los tres héroes "balzacnianos" heredan su fuerza: Minna y Serafitus (que es el primer nombre que se le da al personaje Serafita, título de la novela). La curiosa forma circular, que era, según el filósofo griego, aquella de los andróginos, se halla en Serafita: ella es el centro radiante de un círculo, quienquiera que entra en relación con ella podría verse en un torbellino de claridades. La luminaria lunar tiene un lazo privilegiado con el andrógino de Balzac, heredero del hermafrodita platónico, hijo de la luna. El nacimiento de Serafita es menos importante que su origen fantasmagórico:

Elle semble enfantée par la conjonction de la glace et du soleil. Elle a des regards qui sont fluide lumière, un corps presque phosphorique. (Balzac 1927:197).

Moralmente, ella tiene una naturaleza selénica puesto que es un espejo ${ }^{8}$ donde se refleja la naturaleza moral con sus causas y sus efectos. Cuando ella desaparece, deja toda una huella (una voz en los rayos del sol, un espíritu celeste en las flores nuevas). Ella completa la síntesis del Sol y de la Tierra que realizan los andróginos platónicos: el hermafrodita de Balzac tiene espiritualmente las virtudes de los dos sexos. Serafita obedece a una fusión, la fusión de los dos sexos, reunión de la tierra y el cielo, reunión de los dos seres en los que ella ha suscitado un deseo: Wilfredo y Minna. En esta última empresa, ella aparece como la inversión de la Señorita de Maupin quien no logra jamás reunir en ella los dos sexos, no aproximar ni al hombre ni a la mujer a quienes ha rendido amorosos sentimientos.

Serafitus-Serafita daba pruebas de una erudición considerable y sus facultades mentales sobrepasaban a las de los demás. Balzac describe a este andrógino basado en las teorías de Swedenborg (el hombre perfecto). Este hermafrodita ama a dos seres perfectamente individualizados. Es un hombre perfecto, un ser total.

André Gide en su Tratado de Narciso (1892) imagina a un Adán andrógino, sin diferenciación sexual, antes de su caída. La experiencia del deseo, la entrada en el tiempo y la esperanza engañosa en recrear por medio de la generación la perfección inicial, son signos de una exclusión del Paraíso. En el tiempo feliz de los orígenes, el Adán de Gide, como los personajes de Foigny, estaba integrado al cosmos donde la unidad era representada por el árbol, que reúne, como el huevo primordial de las cosmogonías, la Tierra y el Cielo en una noche protectora: todo se esfuerza hacia la forma perdida, los tiempos paradisíacos pueden recrear a un Narciso que, como Adán antes de la caída, sería contemplativo y negaría todo deseo. En su mirada se vendrían a conciliar todas las diferencias, todos los contrarios. 
André Breton, con su Arcano XVII (1945), juega con una restauración total. É1 le canta a un andrógino encarnado, con superabundancia de lo masculino y lo femenino. Este ser era hijo de la luna, como su arquetipo platónico:

L'ancien etang n'est plus. Toute l'eau a repris son ample respiration sous la crosse de la lune (...) (Miguet 1988: 75).

Breton ve operarse la conjunción activa de los dos sexos amantes de un verso al otro. Un hermafrodita le preexiste y ellos le reconstituyen en virtud de una ley que ve a todo ser humano lanzado a la búsqueda de un ser de otro sexo y así formar uno solo. Marc Eigeldinger ve en el hermafrodita del Arcano XVII un símbolo alquímico: es la materia de la piedra filosofal; sin duda inspirado en los grabados del Rosarium Philosophorum de 1550. El andrógino es la síntesis de los contrarios, el monismo que ha vencido a la conciencia desgarrada por el dualismo.

A los ojos de Breton, Melusine ${ }^{9}$ es la mediatriz entre el hombre y la naturaleza, en Osiris e Isis las oposiciones hombre/mujer, muerte/vida se resuelven en un incesto adélfico, pero este último mito experimenta una actitud de regeneración. La mujer del Arcano derrama con la mano derecha el contenido de una urna de oro, mientras que con la izquierda vacía sobre la tierra una de plata. Esto es una palingénesis de los mitos de Ovidio y Platón. De Platón a causa de la presencia de la tierra, el sol y la luna, por el origen de las tres especies de la humanidad. De Ovidio, a causa del marco acuático, encarnado en la propia Salmacis, y del rol iniciático de la mujer.

Michael Tournier, en su novela Les Metéores (1975), alcanza las formas más antiguas del mito en su doble voluntad de inspirarse en las cosmogonías y en un descubrir la aventura de seres singulares. Tournier hace suya la tradición rabínica según la cual Dios ha hecho al hombre a su imagen y semejanza: masculino y femenino a la vez, hermafrodita. Es de Platón de quien toma el mitema de la separación violenta, el golpe de hacha que nos ha separado, la horrible amputación. Pero para él, el andrógino primitivo subsiste en la célula gemela cuya forma oval tiene relación con los hermafroditas platónicos. Sin embargo, aparentemente la femineidad no tiene lugar en los "amores ovales" de los gemelos Paul y Jean. En realidad su célula contiene en ella los elementos viriles y los elementos femeninos: uno de los gemelos, Paul, es maternal e introvertido; el otro, Jean, es extrovertido, vuelto hacia la conquista del mundo y de la mujer. El fracaso final de sus relaciones personales (Jean se arranca de su gemelo) no es el último motivo de la novela. Amputado de su hermano y de la mitad de su propio cuerpo (el brazo, la pierna le son arrancados, mientras él intenta unir las mitades gemelas y separadas en la ciudad de Berlín), él se inscribe en la mutilación en que Zeus, a los ojos de Platón, había amenazado a la humanidad ya cortada en dos.

Pero la microcélula gemela, imposible de reconstruir, se sustituye con la macrocélula que Paul "reforma" con el universo y la parte aérea, pneumática, meteórica. Así aunque su cuerpo derecho paralizado sea ligado irremediablemente a la tierra (elemento femenino constantemente encarnado por Paul), su cuerpo izquierdo es desplegado sobre el mar como una gran ala sensible. Paul llega a ser, como Salmacis, hija del Cielo y la Tierra.

M. Tournier concilia las viejas cosmogonías del huevo primordial dotado de bisexualidad y el Tercer Testamento anuncia, después de Pentecostés, la difusión del Espíritu Santo. 


\section{Conclusiones}

De la Biblia a Ovidio, pasando por Platón, vemos que los mitos de androginia de la antigüedad tienen las siguientes direcciones: el ser bisexuado puede ser fuente de escándalo o modelo de perfección. Según Marie Miguet, entre estos dos caminos se halla el hombre del dolor o el modelo equívoco. El primero puede vivir en el desgarro pero sin negar su bipolaridad sexual; puede también sentirse definitivamente excluído de la integridad primordial, pues vive la experiencia de la falta del otro. El segundo, el modelo equívoco, toma una iniciativa que se sabe presuntuosa: conjuntar lo que debería estar desunido. La tradición literaria retiene al andrógino como un ser afemeninado, monstruoso, máquina del deseo, consagrado sólo al placer.

Foigny, Balzac y Gide se unen para exaltar en el hermafrodita la unisexualidad conciliadora y la autarquía afectiva. Proust, por otra parte, insiste en los trazos psicológicos de la bisexualidad que testimonian la persistencia de una edad de oro en el hombre actual en vías del hermafroditismo. Muestra que la androginia puede ser restaurada por una creación estética, que bien puede ser aquí el contexto de la moda. Esa creación estética es presentada como una verdadera partenogénesis y ella testimonia a posteriori las posibilidades de la autofecundación: la bisexualidad mental del artista.

La autarquía de la androginia no es sinónimo de esterilidad a los ojos de Foigny, Balzac y Gide o Proust: está acompañada de una fecundidad espiritual.

El texto de Cyrano de Bergerac nos ha llevado a una reflexión: en el contexto grecolatino, la fuente Salmacis es el origen de un tabú: volverse afeminado y perder la virilidad. Jean Libis considera que la androginia, el incesto y el ser gemelo (condiciones todas excepcionales) podrían bien constituir elementos reversibles de un mismo mitologema. Añade, además:

Chacun de ces termes d'une certaine manière, transgresse un ordre, s'oppose à ce qui est donné, s'erige en fantasmagorie. Chacun d'eux abolit une distance et gomme, dans une certaine mesure, une dualité. Chacun d'eux restitue une intimité perdue. (Libis 1988: 72).

El huevo es un principio de totalidad presente en los textos analizados. El huevo primordial es considerado como el germen que contiene todo lo que se desarrolla. En ese nivel del germen, debemos entender la coincidentia oppositorum de los elementos genéricos que, luego de su ruptura, darán como resultado el mundo de las cualidades, es decir, el cosmos. El huevo se separa en dos mitades para dar nacimiento al Cielo y a la Tierra: es la polarización del andrógino. Es una realidad primordial que contiene en germen la multiplicidad de los seres.

Para los likuba y los likuala del Congo, el amarillo del huevo representa la humedad femenina y el blanco, el esperma masculino. Así, un huevo es bisexuado o andrógino pues contiene a los dos principios del género. Veamos lo que dice Chevalier:

Aunque el huevo jamás es absolutamente primero, simboliza sin embargo, el germen de las primeras diferenciaciones. El huevo cósmico y primordial es uno, pero encierra a la vez el cielo y la tierra [principio masculino y femenino], las aguas inferiores y las superiores; en su totalidad única, entraña todas las múltiples virtualidades. (Chevalier 1988: 583) 
Eliade nos dice que el huevo confirma y promete la resurrección, no es un nacimiento, sino un retorno, una repetición. Si consideramos que el hermafrodita estuvo al principio (Ovidio y Platón), sin duda estará al final, cosa de la que hablamos ya en un artículo precedente. Entre la cristiandad, se supone que volveremos a la androginia paradisíaca, prometida aquí en el huevo. Por otra parte, una vez que nos llega la muerte, nuestra alma, presumiblemente, es asexuada. La idea de germen, pero en la vida espiritual, está dada en la tradición alquímica y la obtención del huevo filosófico.

Muchos de los autores analizados concluyen que el hermafrodito es un ser monstruoso y fuera de la realidad. Acerca del monstruo podemos decir que es símbolo de fuerza cósmica tal y como lo es el andrógino según los autores vistos, basados todos en Platón. Es la vida primordial de donde surgió todo: la masa confusa, el Caos. El monstruo es también señal de lo sagrado, como lo extraordinario y lo otro por excelencia (vid. Chinchilla Sánchez, Kattia. 1992. "Mircea Eliade, una clave para la interpretación del pensamiento mítico", 2.4. La hierofanía: manifestación de lo sagrado. Káñina. 16 (1)).

En latín, lengua madre del español, se define la palabra monstrum como "portento", "prodigio", "cosa extraordinaria", "fuera del orden regular", "cosa increíble y prodigiosa"; todas éstas son características de lo sagrado. Aplicado al hombre, es "pernicioso" y "abominable", este rasgo lo conservan y es propio de los seres tabuados que se sacralizan 10 .

En la teoría heroica, vencer al monstruo es vencer a lo inconsciente para reunirse con el anima (nótese aquí de sexo opuesto al héroe) y llegar con ello al selbst o equilibrio psíquico, que no es otra cosa que la reunión de los opuestos sexuales: rey/reina, príncipe/princesa, héroe /damisela (como la celebérrima Dulcinea del Toboso, heroína del caballero de la triste figura). Por tanto, desde el punto de vista junguiano, el hermafrodita no es un monstruo por vencer dentro de lo inconsciente colectivo, sino la representación plástica del selbst. En esta lucha para vencer al monstruo hay una lucha generacional, que en nuestro medio humano es una realidad natural, como dice Homero, cual la generación de la hojas, así la de los hombres: una generación humana nace y otra perece:

(...) heroes rescuing maidens from monsters: the hero striving to dethrone the (Sacred Sun) King by killing him as a monster; he is the maiden's father, and by marrying the daughter he becomes King himself. (Ad de Vries 1984: 325)

Y como en los cuentos de hadas, vivieron felices para siempre...

\section{Notas}

1. Véase aquí la relación con el relato del Génesis.

2. Supónese que así son los ojos de Satanás.

3. Sin embargo, sabemos que su unión con el toro cretense es prueba de su hierogamia con un dios del cielo (unión TORO-VACA/CIELO-TIERRA/MASCULINO-FEMENINO/DIOS-DIOSA/PADRE-MADRE/REY-REINA/HOMBRE-MUJER).

4. Que conduce las almas al Hades. 
5. Esto se contemplaba desde la antigua Grecia, como lo veremos en un trabajo posterior.

6. Los padres de Adonis.

7. Simbolizan el estado de ambivalencia del universo. Aparecen cargados de poderes y fuerzas y por ello son temidos y adorados. Representan los dos opuestos que sintetizan y complementan las funciones.

8. Es símbolo de la sabiduría y del conocimiento. Es un símbolo lunar en el sentido de que la luna refleja la luz del sol como un espejo. Esto es una captación mítica que la ciencia nos lo viene a ratificar: la luna, como un espejo, refleja pasivamente la luz del sol y eso es lo que vemos en la noche de luna llena sobre todo. Como símbolo lunar, lo es también de la mujer y esto se constata con el signo $\odot$, que representa el espejo de Afrodita y representa el principio de lo femenino.

9. Ninfa o hada que desciende de los reyes de Albania. Ella era hija del hada Pressine y encerró a su padre en una montaña para vengar los males cometidos por éste contra la autora de sus días. Por eso ella sería transformada en serpiente de la cintura hacia abajo cada sábado. Melusine se libraría de este suplicio sólo si se casa con un hombre que nunca la vea en este estado. Encuentra uno, se casa y hasta lo hace rico. Pero despertado por la curiosidad, la ve en su baño ritual (propio de las diosas lunares de la fertilidad) y entonces ella desapareció definitivamente en forma de ofidio.

10. Horacio nos habla del monstrum fatale para referirse a la regia egipcia, de la familia de los Lágidas, Cleopatra, célebre por su belleza y por su ambición.

\section{Bibliografía}

Ariosto, Lodovico. 1915. Orlado furioso. Milán: U. Hoepli.

Balzac, Honoré de. 1926. Oeuvres completes. París: Hachette.

Bergerac, Cyrano de. 1924. Historia cómica de los estados e imperios del sol. Madrid: Espasa Calpe.

Boileau, Nicolás. 1961. Satires et épîtres. París: Larousse.

Cirlot, Eduardo. 1985. Diccionario de símbolos. Barcelona: Labor.

Chevalier, Jean y Alain Gheerbrant. 1988. Diccionario de simbolos. Barcelona: Herder.

Chinchilla Sánchez, Kattia. 1992. "Mircea Eliade, una clave para la interpretación del pensamiento mítico”. Káñina 16 (1).

Dante. 1978. La divina comedia. México: Cumbre.

Diccionario literario. 1967. González Porto-Bompiani. Barcelona: Montaner y Simón.

Dictionnaire des mythes litéraires. 1988. París: Editions du Rocher. 
Eliade, Mircea. 1969. Mefistófeles y el andrógino. Madrid: Guadarrama.

Eliade, Mircea. 1981. Tratado de historia de las religiones. Madrid: Cristiandad.

Garibay, Angel Ma. 1980. Mitología griega. México: Porrúa.

Gautier, Théophile. 1918. Mademoiselle de Maupin. París: Charpentier.

Gide, André. 1969. Romans, récits et soties, oeuvres lyriques. París: Gallimard.

Giraudoux, Jean. 1929. Sodome et Gommorre. París: B. Grasset.

Graves, Robert. 1985. Los mitos griegos. Madrid: Alianza

Grimal, Pierre. 1984. Diccionario de mitología griega y romana. Barcelona: Paidós.

Jung, Carl G. 1972. La psicología de la transferencia. Buenos Aires: Paidós.

Jung, Carl G. 1974. El hombre y sus símbolos. Madrid: Aguilar.

Kundera, Milan. 1993. La insoportable levedad del ser. Barcelona: Tusquest.

Musil, Robert. 1986. El hombre sin atributos. Barcelona: Seix Barral.

Ovidio. 1969. Metamorfosis. Barcelona: Iberia.

Pike, Egdar Royston. 1991. Diccionario de religiones. México: F.C.E.

Platón. 1978. Diálogos socráticos. México: Cumbre.

Prampolini, Santiago. 1958. Historia Universal de la literatura. (13 vol.). Buenos Aires: U.T.E.H.A.

Ruiz de Elvira, Antonio. 1988. Mitología Clásica. Madrid: Gredos.

Samain, Albert V. 1900. L'Charriot d'Or. París: Mercvre de France.

Vries, Ad de. 1984. Dictionary of symbols and imagery. Netherlands: Elsevier Science Publishing Company. 